\title{
Email triage is an effective, efficient and safe way of managing new referrals to a neurologist
}

\author{
Victor Patterson, ${ }^{1}$ Jenny Humphreys, ${ }^{2}$ Mark Henderson, ${ }^{1}$ Grainne Crealey ${ }^{3}$
}

'Department of Neurology, Royal Victoria Hospital, Belfast, UK

${ }^{2}$ Visiting Consultants' Team, Erne Hospital, Enniskillen, UK ${ }^{3}$ Senior Health Economist, Clinical Research Support Centre, Royal Victoria Hospital, Belfast, UK

\section{Correspondence to}

Professor Victor Patterson, 58 Lisnabreeny Road East, Belfast BT6 9SS, UK;

vhp498@gmail.com

Accepted 2 January 2010 Published Online First 28 May 2010

\begin{abstract}
Background Patients referred to secondary care in the UK often wait many months to be seen, and the UK government has announced various initiatives to address this issue. Since 2002, we have developed an email referral system which allows some neurological referrals to be managed by advice and investigations rather than by a conventional hospital clinic appointment. This system has previously been shown to reduce clinic attendances and to be acceptable to patients and their general practitioners (GPs).
\end{abstract}

Aim To analyse the effects of an email triage system on waiting times, cost of care and safety over 5 years.

Methods Referral numbers and waiting times for clinics using this system were analysed. Cost was determined by comparing detailed costs with those of conventional care. Safety was analysed by examining the GP records of all patients referred from a single practice who had been dealt with by advice or investigation, noting deaths, re-referrals and changes in diagnosis.

Results Waiting times fell from 72 to 4 weeks, despite an increase in referrals. The cost per patient of email referral was about $£ 100$, compared with $£ 152$ for conventional care, a $35 \%$ reduction. Safety data on 120 individuals showed a minor change in diagnosis in three. Discussion This system is safe, effective (in reducing waiting times) and efficient. It enables neurologists to focus on patients with significant neurological disease and, if applied more widely, could reduce costs and waiting times for neurology services in the UK.

\section{INTRODUCTION \\ Background and problem}

There is a problem in the National Health Service (NHS) in the UK about waiting times for referrals to hospital specialists from primary care. For example, in 2002, the waiting time for a first neurology appointment in Northern Ireland was over 52 weeks. ${ }^{1}$ Essentially, there are just three ways of dealing with this: first, increasing the number of hospital specialists; second, reducing the demand of referral from primary care; and third, dealing with the process differently. We chose the third way because, unlike the first two, it was within our control. A different process had been suggested by our experience of email for neurological problems in Bangladesh. ${ }^{2}$

\section{Purpose of changes}

To determine whether an email triage system could reduce neurology waiting times at a reduced cost and was safe.

\section{METHODS}

\section{Setting and function}

This study took place in Northern Ireland, a UK region with 1.7 million people, at two small rural hospitals where the author was the visiting neurologist; Tyrone County Hospital in Omagh and the Erne Hospital in Enniskillen are a 1.5-2 $\mathrm{h}$ drive from the neurological centre in Belfast and have a combined catchment population of about 120000 people. The study started in 2002 in three general practices. Further practices joined through interest, and in 2004 the author required that all referrals to him from general practice should be by email. Issues of indemnity were considered to be identical to those from letter-referral. There was an alternative attending neurologist throughout the study period who saw referrals conventionally. In 2002 the length of the waiting list to see both neurologists was in the region of 72 weeks. The maximum waiting time decreed by the local NHS became 13 weeks in 2007; patients who exceeded that time were seen by private sector providers.

\section{Intervention}

The system is that described in previous studies. ${ }^{3} 4$ GPs refer by email using a specially designed onepage template. Two email addresses were used, one accessible by the consultant from wherever he happened to be and the other the consultant's secretary, which enabled the referral to be recorded as a clinical episode in the local Patient Administration System (PAS). The referral was anonymised, but a unique Health and Care Number enabled linkage to PAS. The consultant replied to the GP with a copy to the secretary. This reply might ask for further information (about 10\%), give advice about diagnosis and management without the patient being seen, arrange investigations for the patient, again without the patient being seen, or arrange a hospital clinic appointment.

\section{Measures}

Our previous reports had concentrated on satisfaction and feasibility, so we wanted to measure effectiveness in reducing waiting times, costs compared with conventional care and long-term safety.

\section{Effectiveness}

We reviewed the yearly number of GP referrals to both the email service and the consultant offering conventional care between 2002 and 2007, and recorded the waiting times at the end of each year.

Cost

A cost analysis was performed to determine the difference in cost between an email system and 
standard care (consisting of a face-to-face consultation with a consultant neurologist). The retrospective nature of this study did not lend itself to a full economic evaluation (cost-effectiveness or cost-utility analysis). The NHS costs and outcomes associated with both referral pathways are presented separately. Some assumptions had to be made, such as the time spent by healthcare professionals (both GPs and consultant neurologists) and administrative staff under each referral pathway. Time input was calculated by asking each category of staff to estimate the time spent in undertaking a variety of activities (table 1).

Unit costs associated with these activities were then calculated. ${ }^{5}$ In the interests of clarity, both quantities of resources used and unit costs are presented separately. ${ }^{6}$ The proportion of patients in the email referral pathway who received advice, investigation or a clinic visit was provided from analysis of all email referrals in a 12-month period between April 2006 and March 2007. The total number of investigations and reviews from this cohort, including those arising from re-referrals, was included. The review and investigation rates associated with the standard care pathway were taken from a study in the same neurology unit by three different consultant neurologists. ${ }^{7}$ Re-referral rates were not available from this study, and so they were taken as zero.

\section{Safety}

We chose a retrospective cohort of 121 patients from a single practice who had been triaged to receive either advice or investigation and for which at least 6 months' follow-up was available. We informed each patient by letter that this audit would be conducted and gave them the opportunity to opt out if they desired. No patient opted out. The general practice notes, hospital notes and email correspondence were examined to obtain the number of patient deaths, subsequent general practice consultations and re-referrals to the same neurologist or to any other consultant with regard to the referral symptom. We also noted any changes in diagnosis and judged whether these were minor or major. There are no published guidelines for this method of practice, but we felt there should be no related deaths and a major change of diagnosis in less than $5 \%$ of patients.

Table 1 Time estimates and unit cost inputs

\begin{tabular}{lcl}
\hline Staff/activity & $\begin{array}{l}\text { Time estimate } \\
\text { (min) }\end{array}$ & $\begin{array}{l}\text { Unit cost } \\
\text { (£Sterling, 2007) }\end{array}$ \\
\hline Email triage referral management system & & $£ 111 / \mathrm{h}^{*}$ \\
GP email to consultant neurologist & 2 & $£ 11.60 / \mathrm{h} \dagger$ \\
Practice receptionist organising clinic & 10 & \\
visit for patient with hospital & & $£ 11.60 / \mathrm{h}$ \\
Hospital secretary corresponding with GP for patient requiring: & \\
Advice only & 3 & \\
Investigations & 6 & $£ 152 / \mathrm{h} \S$ \\
Clinic visit & 13 & \\
Consultant neurologist time spent dealing with patients requiring: & 5 & \\
Advice only & 15 & \\
Investigations & 25 & \\
Clinic visits & 15 & $£ 111 / \mathrm{h}$ \\
Consultant time spent on review & & $£ 11.60 / \mathrm{h}$ \\
Standard neurology care & 2 & $£ 11.60 / \mathrm{h}$ \\
GP letter to hospital & 7 & \\
Practice receptionist (letter to hospital) & 13 & \\
Hospital secretary (organising clinic & 30 & \\
appointment with patient) & & \\
Consultant neurologist time in clinic & & \\
\hline
\end{tabular}

*Based on the unit cost per hour of GMS activity. ${ }^{5}$

†Based on Admin and Clerical Grade 4 under Agenda for Change (November 2007).

¥Same time estimate was assumed for re-referrals.

$\S$ Based on per hour of patient activity. ${ }^{5}$

\section{RESULTS}

\section{Effectiveness}

The numbers of patients referred to the email consultant and the conventional consultant year on year are shown in figure 1. The total number of referrals per year increased during that period. There was no evidence of increased referral to conventional neurology as the email system became more widely used from 2004. Figure 2 shows the marked effect on waiting times for the email neurologist. These fell from 72 weeks in 2002 to 4 weeks in 2007. The waiting time for conventional referral fell to the NHS target of 13 weeks, as patients waiting longer than that were seen the private sector. There was no obvious change in referral quality over time.

\section{Cost}

In addition to reducing waiting times, the cost of the email referral system resulted in a cost saving of $£ 52.56 /$ patient compared with standard neurology care, representing a reduction of $35 \%$ (table 2 ).

The majority of cost savings were achieved as a result of a reduction in time input from the consultant neurologist (which fell from $£ 76 /$ patient to $£ 31.57 /$ patient, representing a $58 \%$ reduction). The cost of GP time input was higher in the email referral system ( $£ 9.75$ compared with only £3.70) as a few additional minutes had to be spent by the GP in providing feedback to the patient (if they did not require a clinic visit). The cost of time spent by administrative staff in organising clinic appointments was almost negligible. The costs of investigations (mainly MRIs and CTs, costing $£ 224$ and $£ 129$ respectively) made up a sizeable component of the overall cost /patient treated. The costs associated with reviews and referrals were generally a small component of the overall cost/patient. It was assumed that there would be no significant differences in other healthcare costs (such as hospitalisations or medication or hospital overheads) as a result of the introduction of email system.

\section{Safety}

We identified 121 new referrals dealt with by email advice (98) or investigations (21) in the period between 14 February 2001 and 26 August 2005. The exact referral course was unclear in two patients. We were able to obtain the GP records of 120 patients. The mean follow-up from email referral to analysis was 24.5 months (range 6-60 months).

A single death occurred in an 84-year-old woman with essential thrombocythaemia referred with intermittent right-

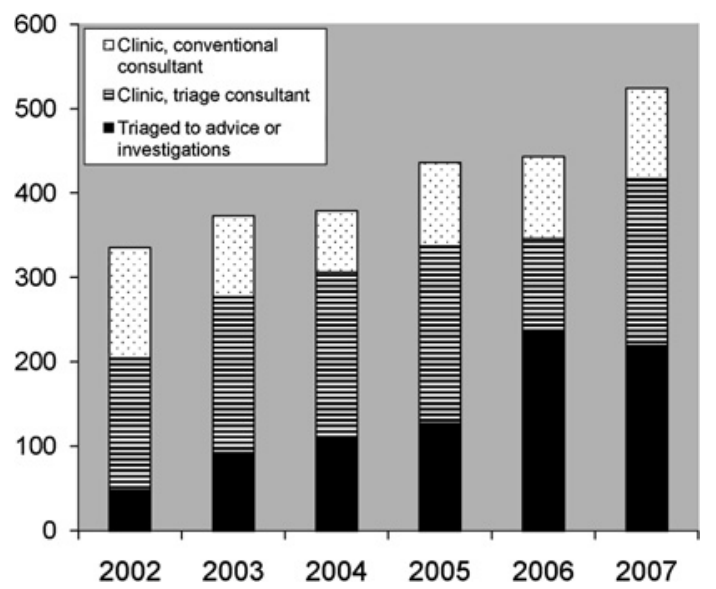

Figure 1 Number of referrals by year and how they were dealt with. 


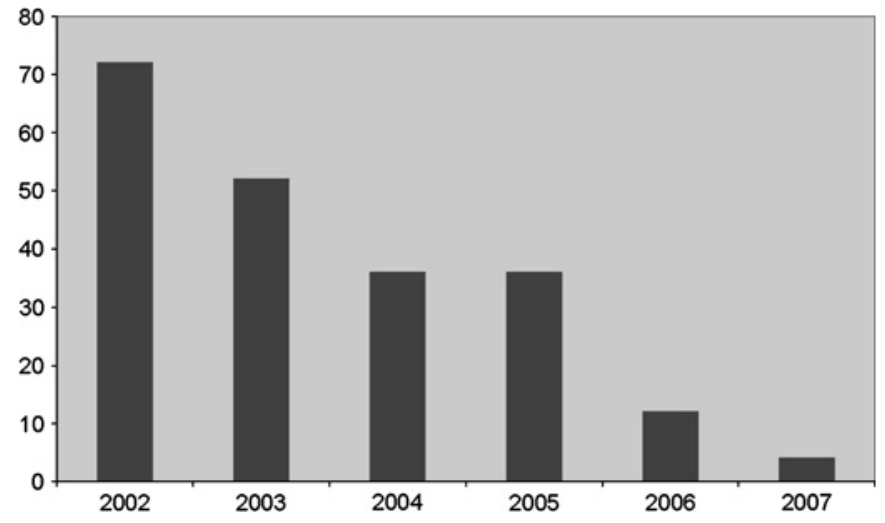

Figure 2 Maximum waiting time in weeks for email triage system.

sided skull pain and given advice. She died of a stroke almost 5 months later.

A total of 16 patients were re-referred to the same consultant, and two of these were referred twice. There were 20 referrals to other consultants in 14 patients. These 36 re-referrals and referrals to other specialists resulted in three changes of diagnosis, all of which were deemed minor (table 3).

The number of re-attendances to GPs after email consultation is shown in figure 3: most patients never attended their GP again with their original symptoms.

\section{DISCUSSION}

\section{Summary}

Compared with conventional care, email triage sees more patients, is safe, costs less and is remarkably effective at reducing waiting times to see a neurologist. Of the six components of quality, safety is the most important, especially in a situation where medicine is practised without seeing the patient. The results in this sizeable population -120 patients with a mean follow-up of 2.5 years-found no significant diagnosis changes and a single unrelated death in patients not seen at the clinic. As is often the case, there are no similar safety studies from conventional outpatient care.

The system has been relatively straightforward to use, although a minority of GPs have not used it for reasons that we have not explored in detail. The majority of GPs have continued to use it despite available conventional care, and we know from previous studies that patients find it acceptable.

\section{Context}

Email triage has been used successfully in Finland ${ }^{8}$ and the $\mathrm{UK}^{9}$ in a number of other specialities and also between a hospital in Bangladesh and specialists in the UK in a mixed group of specialities including neurology. ${ }^{210}$ Email is used by some other UK and

Table 2 Cost of email triage referral management system compared to standard care

\begin{tabular}{llc}
\hline & $\begin{array}{l}\text { Email triage: } \\
\text { cost }(£) / \text { patient }\end{array}$ & $\begin{array}{c}\text { Standard care: } \\
\text { cost }(£) / \text { patient }\end{array}$ \\
\hline Personnel input & 44.54 & 83.49 \\
$\quad$ Neurologist & 31.57 & 76.00 \\
GP & 9.75 & 3.70 \\
Administration & 3.22 & 3.79 \\
Referrals and reviews & 8.20 & 12.16 \\
Investigations & 47.15 & 56.80 \\
Cost/patient & 99.89 & 152.45 \\
\hline
\end{tabular}

Table 3 Changes in diagnosis after re-referral

\begin{tabular}{|c|c|c|}
\hline Original diagnosis & Re-referral specialist & New diagnosis \\
\hline Sinus headache & Original neurologist & Tension-type headache \\
\hline Tension-type headache & Maxillofacial surgeon & $\begin{array}{l}\text { Temporo-mandibular joint } \\
\text { dysfunction }\end{array}$ \\
\hline Tension-type headache & Different neurologist & Migraine \\
\hline
\end{tabular}

Irish neurologists, but the only published report is within the Action on Neurology project from the now-defunct NHS Modernisation Agency, in which only $10-20 \%$ of patients were triaged out of the clinic system. ${ }^{11}$ Part of this difference may be due to different referral symptoms-for example, we triaged $95 \%$ of headaches out of the clinic but only $13 \%$ of weakness.

\section{Interpretation}

The reason for the success of email triage in neurology is probably because there are only a small number of neurological symptoms, all of which can result in either structural disease or disease without structural cause; for example, headache can be due to a brain tumour (serious) or a muscle tension headache (not serious). Skilled clinical neurologists can probably distinguish between the two by reading a good history on an email. Many non-structural symptoms get better on their own without further intervention of any sort, let alone a neurology clinic attendance. Indeed, $75 \%$ of patients in our safety study never attended their GP again with that symptom.

This system meets all the hallmarks of quality laid down by the American Institute of Medicine ${ }^{12}$ - safety, effectiveness, efficiency, equity, timeliness and patient-centredness. The equity issue is particularly important because GPs have differing thresholds for referral to secondary care. If GPs have a low threshold for referral, then the waiting list will increase for GPs who have a high threshold for referral, and they will be relatively disadvantaged. With this system many of the referrals of the high-referring GPs will be triaged out of the clinic system, so patients will end up in the clinic seeing the neurologist based on clinical need, rather than their GP's threshold for referral.

\section{Limitations}

The weakness of this study is that it was carried out by a single neurologist who was relatively experienced in clinical neurology.

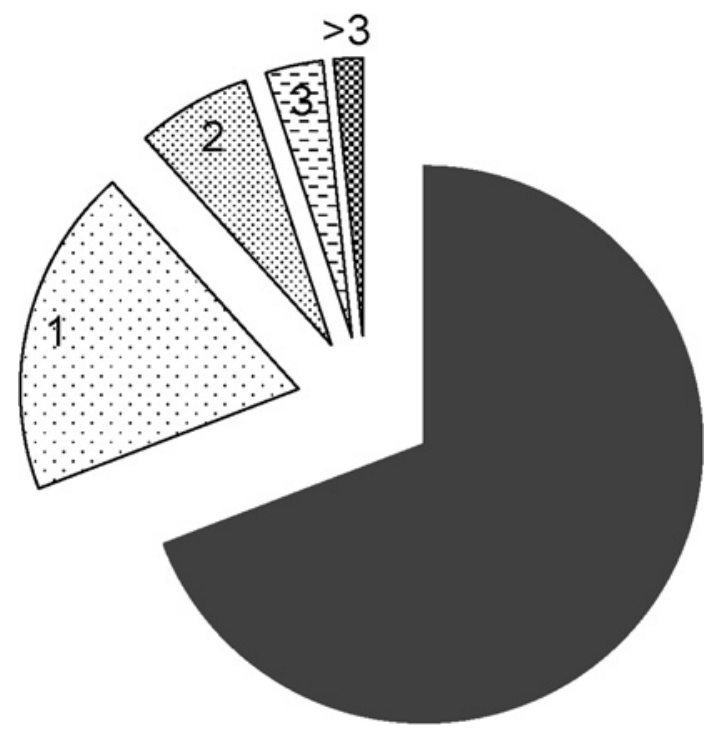

Figure 3 Number of visits to GP for the same symptom after being dealt with by advice or investigations. 
Whether or not similar results would be obtained by less experienced neurologists is not known. It is tempting to speculate that any trained neurologist should be able to triage referrals in this way and that the magnitude of the effect would depend, among other things, on their clinical competence.

\section{Conclusions}

The email system is $35 \%$ less costly than standard referral. In addition to a reduction in waiting time (the monetary value of which has not been incorporated into this analysis), it reduces cost via the reduction in time input by the consultant neurologist (which could then be redirected into other activities). The high degree of diagnostic accuracy observed, and lack of significant increases in referrals, reviews or investigations, suggests that its widespread introduction into routine practice could save the NHS money. We have not looked at cost savings to individuals and their families by avoiding a trip to hospital.

One barrier to increased uptake is that there is a belief among neurologists that they cannot give an opinion without examining the patient in person. Yet almost all doctors do give opinions without seeing the patient in some circumstances. Another is that doctors think that patients do not like this method of being dealt with. Our previous studies have shown that patients prefer it to waiting a longer time to see a neurologist in person. ${ }^{13}$ Patient acceptability in the telemedicine literature is high. ${ }^{14}$

The results of this study are especially relevant, as referral management systems are being advocated in the reform of the UK NHS. ${ }^{15}$ We have shown very clearly that email triage by an experienced neurologist is probably unique in clinical practice; a safe procedure which reduces clinic waiting times for less cost.

\section{Postscript}

The first author retired in June 2008. Six months before that, he was asked to apply this triage system to the population of Belfast. This required formal involvement of his employing health Trust and the commissioning health Board. Local GPs were enthusiastic, but an Information Technology committee of the Board questioned his use of an email account outside the NHS, even though there was no patient-related data other than an NHS Health and Care Number. The NHS email system was unable to provide the necessary accessibility from outside the NHS, so this project foundered.
Despite having given 6 months' notice of his intention to retire, he was not replaced for another 9 months. Unsurprisingly, the outpatient waiting time in Omagh and Enniskillen rapidly reverted to the 13-week government-declared maximum.

Throughout Northern Ireland, this is maintained at 13 weeks by dint of waiting list initiative clinics paid for by the NHS but performed privately, often by the very consultants whose waiting lists are being kept to 13 weeks. This provides a strong financial incentive for consultants to continue to practise inefficiently and makes changing to an email triage system a poor business decision. At present, the NHS does not provide any similar inducements to practise efficiently.

Competing interests VP is founder and Chairman of Synapse Teleneurology Ltd.

Provenance and peer review Not commissioned; externally peer reviewed.

\section{REFERENCES}

1. Neurology waiting lists in Northern Ireland. 2004. http://www.dhsspsni.gov.uk/ waiting lists mar04.pdf (accessed 30 Sep 2009).

2. Vassallo DJ, Hoque F, Roberts MF, et al. An evaluation of the first year's experience with a low-cost telemedicine link in Bangladesh. J Telemed Telecare 2001;7:125-38.

3. Patterson V, Humphreys J, Chua R. Email triage of new neurological outpatient referrals from general practice. J Neurol Neurosurg Psychiatry 2004;75:617-20.

4. Patterson V, Humphreys J, Chua R. Teleneurology by email. J Telemed Telecare 2003;9(Suppl 2):S42-3

5. Curtis L. Unit costs of health and social care. Canterbury, UK: Personal Social Services Research Unit, University of Kent, 2007.

6. Drummond M, Manca A, Sculpher M. Increasing the generalizability of economic evaluations: recommendations for the design, analysis, and reporting of studies. Int $J$ Technol Assess Health Care 2005;21:165-71.

7. Chua R, Craig J, Esmonde T, et al. Telemedicine for new neurological outpatients: putting a randomized controlled trial in the context of everyday practice. J Telemed Telecare 2002;8:270-3.

8. Harno K, Paavola T, Carlson $\mathrm{C}$, et al. Patient referral by telemedicine: effectiveness and cost analysis of an Intranet system. J Telemed Telecare 2000;6:320-9.

9. Pal B, Laing H, Estrach C. A cyberclinic in rheumatology. J $R$ Coll Physicians Lond 1999:33:161-2.

10. Patterson V, Hoque F, Vassallo D, et al. Store-and-forward teleneurology in developing countries. J Telemed Telecare 2001;7(Suppl 1):52-3.

11. http://www.natpact.nhs.uk/uploads/2005_Apr/Action_On_Neurology.pdf laccessed 20 Dec 2009).

12. Anon. Improving the 21st century healthcare system. InInstitute of Medicine Committee on Quality Healthcare in America, ed. Crossing the quality chasm: a new health system for the 21st century. Washington, DC: National Academy Press, 2001:39-60.

13. Patterson V, Donaghy C, Loizou L. Email triage for new neurological outpatient referrals: what the customers think. J Neurol Neurosurg Psychiatry 2006:77:1295-6.

14. Mair F, Whitten P. Systematic review of studies of patient satisfaction with telemedicine. BMJ 2000;320:1517-20.

15. Davies M, Elwyn G. Referral management centres: promising innovations or Trojan horses? BMJ 2006;332:844-6. 